ORDERED LIBERTY 



\title{
Ordered Liberty
}

\section{A CONSTITUTIONAL HISTORY OF NEW YORK}

\author{
by \\ Peter J. Galie
}

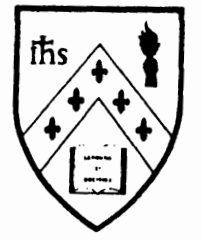

Fordham University Press

New York 
Copyright $\mathbb{1} 1996$ by Fordham University Press

All rights reserved

LC 95-31878

ISBN 0-8232-1651-9

Library of Congress Cataloging-in-Publication Data

Galie, Peter J.

Ordered liberty : a constitutional history of New York. p. $\mathbf{c m}$.

Includes bibliographical references and index.

ISBN 0-8232-1651-9

1. New York (State)-Constitutional history. I. Title. KFN5681.G35 1995

$342.747^{\prime} 029-\mathrm{dc} 20$

[347.470229]

$95-31878$

CIP

ISBN 0-8232-1652-7 (paperback)

Second printing 2001 
To Frannie 
